\title{
Una experiencia inédita del sector privado
}

\author{
Rigoberto Monge \\ Coordinodor del Sector Privodo poro el TIC con México
}

S eis años de negociaciones ininterrumpidas para alcanzar finalmente un Tratado de $\mathrm{Li}$ bre Comercio entre los paises del Triángulo Norte de Centroamérica (El Salvador, Guatemala y Honduras) y México. es un largo periodo en el que las partes han tenido cambios de Presidentes por la debida alternancia democrática y, por supuesto, cambios de Ministros de Economía o de Comercio. Usualmente los máximos responsables de la política comercial de estos paises. Sin duda, estos cambios, entre otros como los de las crisis económicas y financieras que se han hecho presentes en el escenario internacional, han incidido en la duración del plazo de la negociación.

A los factores anteriores, cabria agregar en el ámbito del sector empresarial las naturales expectativas de diferente signo que encerraba la participación por primera vez en la negociación de un Tratado de Libre Comercio. Ello particularmente por la comple jidad e integridad del instrumento comercial que finalmente se negoció, y por haberse realizado con un socio comercial amigo que presentaba el elevado perfil de una exitosa politica económica y que recién venía de concluir con coronas de éxilo un Tratado de Libre Comercio con la primera potencia económica mundial, los Estados Unidos de América, y con Canadá. Los desafíos estaban claramente delineados.

El escenario se tornaba aún más desafiante para el sector privado, no solamente por la circunstancia de las estadisticas comerciales que actuaban en cierto modo en la dirección aparentemente contraria para proyectar al país un TLC con México, sino también porque el esfuerzo de la participación habría que extenderlo a la coordinación y armonización de posiciones con nuestros paises hermanos colegas del proyecto de la integración económica centroamericana, Guatemala y Honduras, visto que asi eran las directrices de los Gobiernos.

Finalmente, el marco general de esta negociación para el sector privado también encerraba dos factores igualmente novedosos: uno, haber experimentado modalidades de consulta con el sector productivo en las que se intentó conjugar el trabajo con las empresas y con las principales gremiales empresariales; $y$, dos, haber trabajado en estrecho contacto con el equipo gubernamental de negociación sabiendo que por un lado se trababa de un ensayo, que afortunadamente funcionó en la gran mayoría de los casos, y por otro la participación del sector privado linitada a la modalidad definida como el Cuarto de al Lado. Esta modalidad of recia pocas posibilidades de actuación directa y su función se limitaba a facilitar las consultas, aspecto de suyo muy importante.

\section{Expectativas del TLC}

El Tratado recién concluido y que se prepara para ser firmado el 29 de junio 2000, contiene centenares de acuerdos producto de la negociación en variados ámbitos, tales como las reglas y disciplinas de comercio que han de regular el libre intercambio entre los paises suscriptores, la propiedad intelectual, las reglas de origen, la inversión, las prácticas desleales de comercio. los procedimientos aduaneros, las medidas de normalización. el comercio de servicios, las compras gubernamentales, las facilidades de movilidad para los hombres de negocios, entre otros.

De esta forma, a partir de la vigencia del Tratado una vez ratificado por los Organos Legislativos de los paises miembros, el millonario intercambio comercial tendrá por primera vez un marco regulatorio completo y directo. Este moderno cuerpo de normativas y reglas deberá asegurar tanto el libre acceso de los bienes y servicios a los respectivos mercados como la práctica del comercio leal.

Gracias al compromiso de la consolidación de las medidas comerciales, la protección de las concesiones y la debida transparencia que caracterizan de manera general este Tratado, los actores y protagonistas reales de la actividad económica, es decir el sector empresarial. podrán disponer de un marco de seguridad, permanencia y predictibilidad en su comercio con México. No habrán cambios abruptos en la norinativa comercialy aduanera, salvo las excepciones contempladas, mismas que

'Los opiniones oqui vertidos son o rítulo personol. 
Una experiencia inédila del sector privado

el tratado de libre comercio con México

se derivan cle los compromisos multilaterales del comercio (OMC). que en todo caso deberán ser notificadas y respaldadas con la debida anticipación entre las partes. En esta misma linea, el TLC igualmente contiene los recursos adecuados para encontrar la solución a las diferencias comerciales que llegaren a suscilarse comoresulrado de la aplicación del mismo.

Los márgenes de asimetria a favor cle los paises del Triángulo Norle referidos al acceso al mercado de los bienes industriales y agropecuarios. son sei iales de ticmpo o plazos en la mayoría de las veces para dar lugar a la debida preparación o reconversión de la planta producliva local para participar adecuadamente en los mercados cada vez más competitivos. Los márgenes cle asimetria llegan a cubrir periodos de hasta once años. En esıe mismo orden, podria mencionarse el caso cle los productos excluidos.

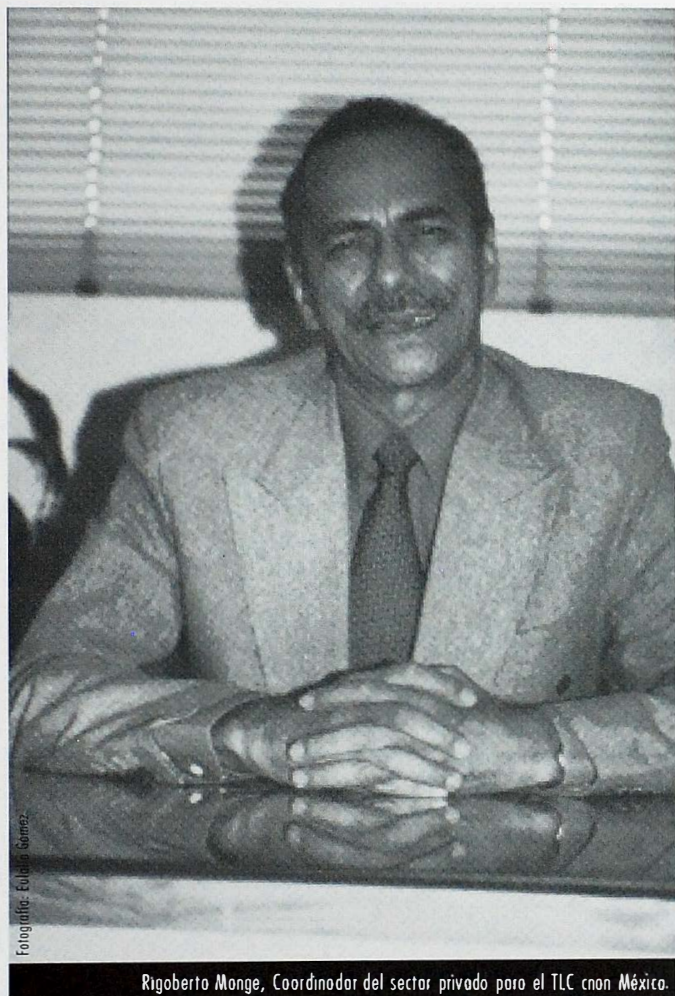

Salvo unos pocos productos de particular interćs para algunos de los países del Triángulo Norte. la negociación conjunta de El Salvador; Guatemala y Honduras ante México ha signilicado un positivo ejercicio de coordinación y bases para una armonización en materia de politica comercial en el contexto cle los proyectos estratégicos de la integración económica centroamericana, ıales como los planteados bajo el tema de la unión aduane ra. Para el sector privado en particular, el trabajo conjunto cle los tres países se ha traducido en mayores niveles cle acercamiento y comunicación entre las diversas ra mas de la producción.

Las cxpeclativas del TLC con México son grancles Es un valioso recurso de integración comercial en el yuc la libre circulación cle los bienes y servicios pondrá en movimiento un mercido de 120 millones de personas. Sin cluda. ante semejantes dimensiones. los retos hacia una mavory me jor preparación de nuestras empresas son grancles.

\section{La administración de los Tratados Comerciales.}

El relo cle la preparación, aún con la aparente adversiclacl cle los tiempos, también alcanza a las instituciones del sector público. especialmente en lo que respecta a la administración del voluminoso paquete de acuerdos que encierran los tratados y los acuerdos comerciales suscritos y por suscribir por parte del Gobierno. Se tiene conocimiento de que se hacen preparativos en esta dirección, para lo cual el secior produclivo se encuentra en la mejor disposición de colaborar Iras delinir los mejores métodos de trabajo en el que se privilegie la función facilitaclora de! Estado.

Los retos del mejor aprovechamiento de los trallados y acucrdos comerciales pasan por el includible camino de su contribución para mejorar las condiciones de empléo y bienestar de nuestra población. El pais necesila de más y mejores empleos. Y de más inversión en capital humano.

Haber concluido al esta fecha la negociación de tres Iratados de libre comercio, con República Dominicana. Chile y. Mexicogenera una valiosa oportunidad paraevaluar las experiencias y lecciones aprendidas en el proceso de las negociaciones. Todo lo experimentado es positivo. Solamente que algunos aspecios. modalidades y meiodos de trabajo: la participación; los enfoques estratcigicos: los estudios previos de impacio económico. comercial y social: el alcance de la agenda comercial de los próiimos cinco atios. entre otros. son temas del mavor interes del sector privado a fin de acumular lo aprendido como una valiosa inversión del pais. 